\title{
Assessment of anti-dislodgment capability for contemporary drug eluting stents
}

\author{
Yicong Ye*, Xiliang Zhao*, Yong Zeng \\ Beijing Institute of Heart, Lung and Blood Vessel Diseases, Beijing Anzhen Hospital, \\ Capital Medical University, Beijing, China
}

Stent dislodgment is one catastrophic complication of percutaneous coronary intervention (PCI), especially in tortuous and calcified lesions. The anti-dislodgment capability of different stent platforms may be varied due to different designs. However, data on the anti-dislodgment capability of contemporary stent platforms are still unavailable. Thus, the aim herein, was to compare the antidislodgment capability of different stent platforms with a bench test.

Three types of stent platforms ( $\mathrm{n}=3$ for each stent platform) were included in the bench test, including XIENCE Xpedition $(3.0 \times 23 \mathrm{~mm}$, Abbott), Resolute Integrity $(3.0 \times 22 \mathrm{~mm}$, Medtronic), Synergy $(3.0 \times 24 \mathrm{~mm}$, Boston Scientific). The antidislodgment capability was assessed by Instron 5943 (Boston, US). Appropriate stent holder was determined according to the profile measurement of each stent (Inner diameter of stent holder $=$ $=$ measured stent profile $-2 \times$ structs thickness). The force was recorded during the pullback process with the speed of $50.8 \mathrm{~mm} / \mathrm{min}$. Maximal dislodgement force was defined as the first peak value of the force record in $5 \mathrm{~mm}$ pullback. Operators were blinded to the brands of the stent platforms. Study design was in accordance with two standard guides from China (standard guide for measuring securement of balloon expandable vascular stent mounted on delivery system, YY/T 0807-2010, https://www.chinesestandard.net/China/Chinese. aspx/YYT0807-2010; Cardiovascular implants Endovascular devices. Part 2: Vascular stents, YY/T 0663.2-2016, https://www.chinesestandard.net/
China/Chinese.aspx/YYT0663.2-2016). Data were presented as median [interquartile range]. Group comparisons were performed using the Kruskal-Wallis test with a post-hoc test. All statistical tests were performed using GraphPad Prism version 5.00 (GraphPad Software, San Diego California USA) in a two-sided manner. Values of $\mathrm{p}<0.05$ were considered statistically significant.

The recorded force of each stent during the pullback process was presented in Figure 1A-C. The median of maximal dislodgement force for 3 stent platforms was as follows: XIENCE Xpedition group: $10.31 \mathrm{~N}$; Resolute Integrity group: $6.93 \mathrm{~N}$; Synergy group: $6.19 \mathrm{~N}$. There were significant differences among the three groups $(\mathrm{p}=0.027)$. Group comparisons indicated that XIENCE Xpedition had higher maximal dislodgement forces than the Synergy group (10.31 [9.76-10.33] N vs. 6.19 [5.48--6.50] N, $\mathrm{p}=0.022$ ), while there was no difference between the Resolute Integrity and Synergy groups $(6.93$ [6.64-7.00] N vs. 6.19 [5.48-6.50] N, $\mathrm{p}=0.539)$, or between Resolute Integrity and XIENCE Xpedition (6.93 [6.64-7.00] N vs. 10.31 [9.76-10.33] N, p = 0.539) (Fig. 1D).

Stent dislodgment is an uncommon complication during PCI which is primarily due to calcification and tortuosity of the lesion. The prevalence of stent dislodgement was up to $\sim 8 \%$ in the early 1990s [1]. Fortunately, the rate of stent dislodgement has significantly decreased which may be explained by the increased operator experience and advancement in stent technology [2]. Several parameters of stent platform including profile,

Address for correspondence: Dr. Yong Zeng, Beijing Institute of Heart, Lung and Blood Vessel Diseases, Beijing Anzhen Hospital, Capital Medical University, No. 2, Anzhen Road, Chaoyan District, 100029, Beijing, China, tel: 86-10-64456159, fax: 86-10-64456159, e-mail: anzhenzy@163.com

Received: 27.02.2020 Accepted: 16.05.2020

*Yicong Ye and Xiliang Zhao contributed equally to the study.

This article is available in open access under Creative Common Attribution-Non-Commercial-No Derivatives 4.0 International (CC BY-NC-ND 4.0) license, allowing to download articles and share them with others as long as they credit the authors and the publisher, but without permission to change them in any way or use them commercially. 


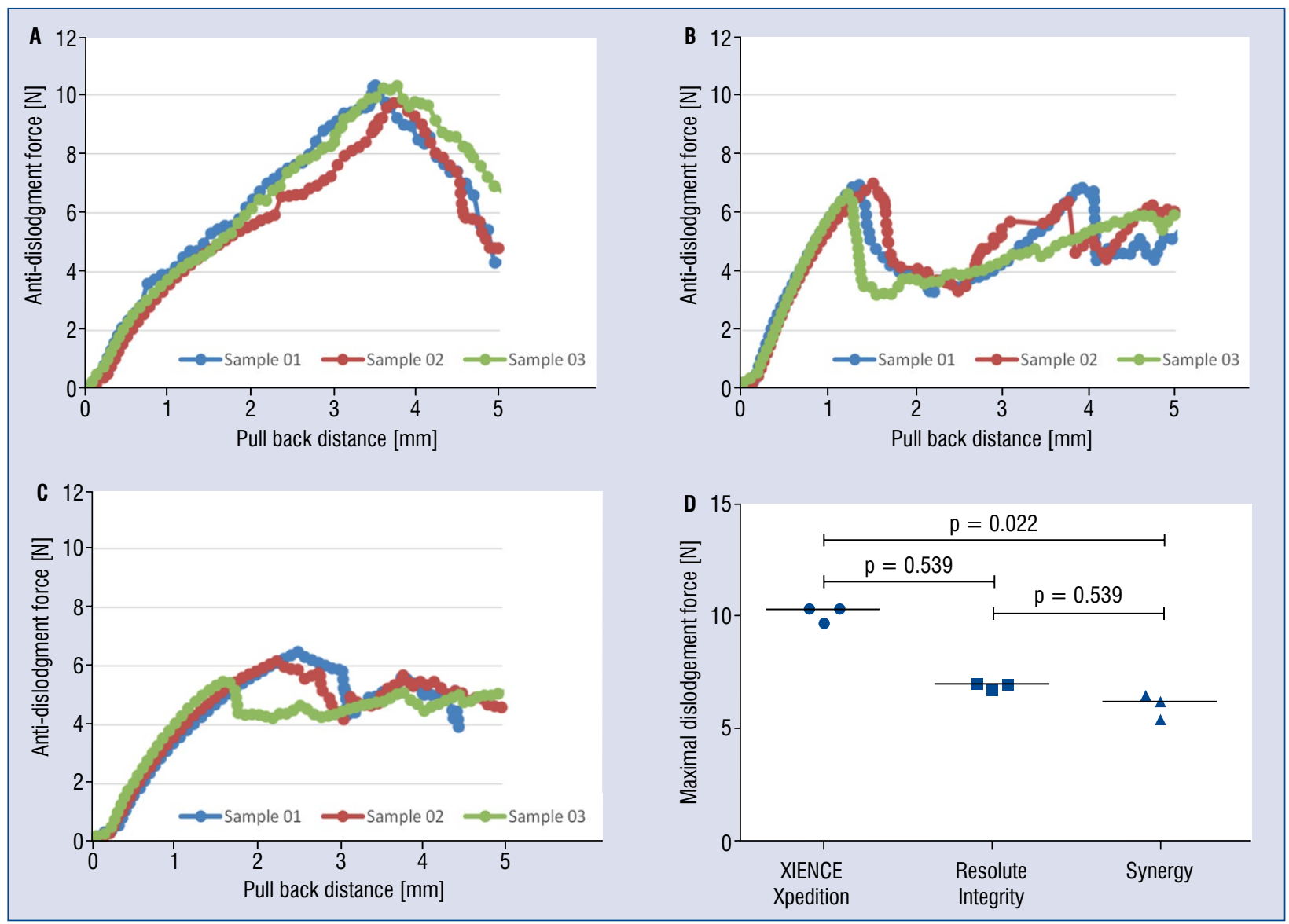

Figure 1. The values of force $(\mathrm{N})$ during the pullback process for different drug eluting stents (with the speed of $50.8 \mathrm{~mm} / \mathrm{min}$ ). The force curves recorded in $5 \mathrm{~mm}$ pullback for XIENCE Xpedition (A), Resolute Integrity (B), and Synergy (C); D. Comparison of maximal dislodgement force among three drug eluting stents.

flexibility, and adhesion are associated with risk of stent dislodgment. Data on the profiles of commercial stents are available and some studies have provided a numerical approach to assess the stent flexibility [3]. However, so far there are no published data evaluating the adhesion of stent platforms. The present study is the first study to assess stent adhesion with numerical data, which is one of the major components of anti-dislodgment capability. There are some potential explanations for the difference in maximal dislodgment force among three types of drug eluting stents (DES). First, stent platforms vary among different DES. XIENCE Xpedition and Resolute integrity stents use a cobalt chromium platform with MULTI-LINK and continuous sinusoid designs, respectively. On the other hand, Synergy uses the platinum chromium platform with a different number of connectors (e.g. 4 connectors on proximal end and 2 connectors throughout body for 2.50-3.50 $\mathrm{mm}$ stents). Second, the stent crimping technique is a key determinant for maximal dislodgment force. However, stent crimping techniques for different DES are patented and are not available to the public. The current study has several limitations. First, the sample size was small. Second, an in-vitro study could not provide the same environment as in the coronary arteries. Finally, the latest generation of DES such as XIENCE Sierra or Resolute Onyx were not used.

Current bench test found that anti-dislodgment capability varied among the stent platforms and XIENCE Xpedition may be higher than Resolute Integrity and Synergy. Further study is needed to verify this preliminary result.

\section{Acknowledgements}

This study was supported by The National Key research and development Program (2018YFC1312801).

Conflict of interest: None declared 


\section{References}

1. Schatz RA, Baim DS, Leon M, et al. Clinical experience with the Palmaz-Schatz coronary stent. Initial results of a multicenter study. Circulation. 1991; 83(1): 148-161, doi: 10.1161/01. cir.83.1.148, indexed in Pubmed: 1984878.

2. Kwan TW, Chaudhry M, Huang Y, et al. Approaches for dislo-dged stent retrieval during transradial percutaneous coro- nary interventions. Catheter Cardiovasc Interv. 2013; 81(6): E245-E249, doi: 10.1002/ccd.24483, indexed in Pubmed: 22581524.

3. Petrini L, Migliavacca F, Auricchio F, et al. Numerical investigation of the intravascular coronary stent flexibility. J Biomech. 2004; 37(4): 495-501, doi: 10.1016/j.jbiomech.2003.09.002, indexed in Pubmed: 14996561. 